\title{
Epidemiological survey of workers exposed to inorganic germanium compounds
}

\author{
B Swennen, A Mallants, H A Roels, J P Buchet, A Bernard, R R Lauwerys, D Lison
}

\begin{abstract}
Objectives-To assess occupational exposure to inorganic germanium (Ge) in workers from a producing plant, and to assess the health of these workers, with a special focus on respiratory, kidney, and liver functions.

Methods-Cross sectional study of 75 workers exposed to $\mathrm{Ge}$ and 79 matched referents. Exposure was characterised by measuring air and urine concentrations of the element during a typical working week, and health was assessed by a questionnaire, clinical examination, lung function testing, chest radiography, and clinical chemistry in serum and urine, including high and low molecular weight urinary proteins.
\end{abstract}

Results-Airborne concentrations of Ge (inhalable fraction) ranged from 0.03 to $300 \mu \mathrm{g} / \mathrm{m}$, which was reflected by increased urinary excretion of Ge $\mathbf{( 0 . 1 2 - 2 0 0}$ $\mu \mathrm{g} / \mathrm{g}$ creatinine, after the shift at the end of the working week). Lung, liver, and haematological variables were not significantly different between referents and workers exposed to Ge. A slightly higher urinary concentration of high molecular weight proteins (albumin and transferrin) was found in workers exposed to Ge, possibly reflecting subclinical glomerular changes. No relation was found between the intensity or duration of exposure and the urinary concentration of albumin. No difference between referents and workers exposed to $\mathrm{Ge}$ was found for other renal variables.

Conclusions-Measurement of urinary Ge can detect occupational exposure to inorganic Ge and its compounds. It is prudent to recommend the monitoring of renal variables in workers exposed to $\mathrm{Ge}$. (Occup Environ Med 2000;57:242-248)

Keywords: inorganic germanium; occupational exposure; biological monitoring

Germanium $(\mathrm{Ge})$ is not a scarce element in nature as its concentration in the earth's crust averages $7 \mathrm{ppm}$, which is similar to that of lead and zinc. It is also a ubiquitous component of living organisms, but there is no evidence that it is essential for plants, animals, or humans. The diet is the main source of $\mathrm{Ge}$ intake in humans (0.4-1.5 mg Ge a day). Some foodstuffs including sea foods, oats, tomato juice, garlic, or ginseng may contain appreciable amounts of this element, which is very well absorbed after ingestion (>90\% in humans). ${ }^{1}$
Although the alleged therapeutic value of Ge (stimulating the use of iron and haemoglobin production) was never generally accepted and eventually abandoned, dietary Ge supplements have been very popular. ${ }^{2}$ Long term intake of $\mathrm{Ge}$ based nutritional supplements or health producing elixirs may even represent a hazard to human health. This has been well documented by several reports on subjects who ingested large doses of these over the counter preparations, usually consisting of mixtures containing $\mathrm{GeO}_{2}$, carboxyethyl $\mathrm{Ge}$ sesquioxide (Ge-132), or Ge-lactate-citrate. ${ }^{3}$ Case reports mostly deal with severe adverse effects on the kidney, including several deaths, but other health effects have included anaemia, myopathy, and peripheral neuropathy. ${ }^{2-4}$ Experimental studies with oral administration of Ge have corroborated most of these findings. ${ }^{3}$ In laboratory animals, impaired liver and kidney function was found after lifetime consumption of $5 \mathrm{ppm} \mathrm{Ge}$ in drinking water. Chronic oral administration of $\mathrm{GeO}_{2}$ resulted in notable dose dependent nephrotoxic effects in rats whereas pure Ge-132 did not. ${ }^{5}$ Also, excessive oral absorption of inorganic Ge compounds ( $\mathrm{GeO}_{2}$, sodium germanate) has been found to produce toxic effects on skeletal muscle ${ }^{6}$ and bone mineralisation. ${ }^{7}$

In industry, $\mathrm{Ge}$ is an economically and strategically important metal, and is mainly produced through the processing of residues recovered during metallurgical treatment of zinc or lead-zinc-copper ores. World wide, the production of inorganic Ge compounds (metallic $\mathrm{Ge}, \mathrm{GeCl}_{4}, \mathrm{GeO}_{2}$ ) may be 30-100 tonnes or more. Metallic Ge is destined for manufacturing high technology products-such as $\mathrm{Ge}$ glass for infrared optics, semiconductor electronics, and highly pure single crystals for $\gamma$ ray spectroscopy detectors. $\mathrm{GeCl}_{4}$ is widely used in the production of optical fibres and represents the basic compound for the production of $\mathrm{GeO}_{2} \cdot \mathrm{GeO}_{2}$ is used as a catalyst in polyethylene terephtalate production, as the starting material for the synthesis of organoGe compounds, and for the manufacture of luminous objects and bismuth germanate crystals for scintillation detection. In these industrial settings, occupational exposure occurs mainly through inhalation of airborne particulate of elemental $\mathrm{Ge}$ and $\mathrm{GeO}_{2}$ dust.

Besides the abundant toxicological data on Ge compounds taken orally, inhalation toxicity of $\mathrm{Ge}$ compounds is much less documented. In rats exposed to metallic $\mathrm{Ge}$ or $\mathrm{GeO}_{2}$ by inhalation, the kidney and the lung were reported as the main target organs, effects on the the lung being apparently more marked in animals 
exposed to high doses of the metal. ${ }^{8} \mathrm{GeCl}_{4}$ vapours are known as strongly irritating to the respiratory system, skin, and eyes and exposure to $\mathrm{GeH}_{4}$ gas may cause haemolysis. ${ }^{10}$ Inhalation exposure to $\mathrm{GeCl}_{4}$ in rodents induced pulmonary, hepatic, and renal adverse effects. ${ }^{1}$ To our knowledge, there is no study in humans that examined inhalation exposure to inorganic $\mathrm{Ge}$ compounds and its possible health effects.

The present study was carried out in one of the most important production plants of $\mathrm{Ge}$ in the world. The aims were $(a)$ to assess occupational exposure to inorganic $\mathrm{Ge}$, and $(b)$ to assess the health of the workers, with a special focus on respiratory, kidney, and liver functions.

\section{Materials and methods}

STUDY POPULATION AND DESIGN

This Ge plant is part of a large metallurgical concern and uses a wide variety of side stream products from the zinc industry. Ge is extracted and refined through a series of pyrometallurgical and hydrometallurgical steps. During this process $\mathrm{GeCl}_{4}$ and $\mathrm{GeO}_{2}$ are produced, and after further physical purification, refining and crystal pulling Ge metal is obtained for optical and electronic applications. The total workforce of this plant comprised 80 people when this survey was started. One worker did not participate because of sick leave and four other people were excluded from the cohort because of unreliable measurement of exposure. None of the workers from this cohort needed to be excluded for medical causes (renal, liver, or lung disease, or occupational exposure to other chemicals toxic to the kidney, liver, or lung). The final group included 75 male workers; 50 of them were mainly exposed to Ge metal, six others to $\mathrm{Ge}$ oxide and metal, six others to Ge oxide and tetrachloride, and the remaining 13 workers had variable exposure. A group of 79 control workers who had never been in contact with $\mathrm{Ge}$ was recruited from other departments of the same company (transport, warehouse, general services, and administration). Because all workers lived in the same region, worked in the same company, and were subjected to similar hiring criteria and occupational health programmes, an efficient matching between controls and exposed workers was achieved for educational and socioeconomic status.

Two groups of ex-Ge workers $(n=11)$ who retired in June 1992 after 20-35 years of work in the Ge unit and of age matched controls $(n=11)$ were also examined.

Each worker was examined during a typical working week which followed a weekend off. At the beginning (Monday) and at the end (Friday) of this week, urine and blood was collected in the morning (0600, before the shift), the worker was then equipped with a pump for personal sampling of airborne Ge during the 8 hours, and a second sample of urine was obtained at the end of the working day (1400, after the shift). None of the workers wore respiratory protection. Clinical examination, chest radiology, and pulmonary function tests were taken on Tuesday of the same working week.

ANALYSIS OF Ge IN URINE

A novel method based on flow injection graphite furnace atomic adsorbtion spectroscopy (FI-GFAAS) was developed for the measurement of $\mathrm{Ge}$ in urine. It essentially comprises five consecutive steps, mineralisation of urine, $\mathrm{pH}$ conditioning, generation of gaseous $\mathrm{GeH}_{4}$ by flow injection, $\mathrm{GeH}_{4}$ trapping in an iridium coated graphite furnace, and ultimate electrothermal atomisation of Ge. Wet mineralisation of a typical aliquot of urine $(15 \mathrm{ml})$ was performed with a programmable digestion system (Tecator 40: Digester 1016, and Autostep 1012 controller). In a second step, the mineralisate based on $\mathrm{H}_{2} \mathrm{SO}_{4}$ was diluted with $10 \mathrm{ml} \mathrm{0.4} \mathrm{M} \mathrm{KH}_{2} \mathrm{PO}_{4}(\mathrm{pH} 6.0$ ), then the $\mathrm{pH}$ was adjusted to a value between 5.5 and 6.0. The mineralisate was further diluted with Nanopure water to a final volume of $30 \mathrm{ml}$. The third step involved an FIAS-400 Perkin Elmer flow injection analysis to produce gaseous $\mathrm{GeH}_{4}$ by addition of $0.4 \%$ aqueous $\mathrm{NaBH}_{4}$ that was conveyed by the carrier gas in a pyrolytic iridium coated graphite L'vov platform furnace atomiser preheated to $400^{\circ} \mathrm{C}$ and mounted on a Perkin Elmer Zeeman 4100ZL atomic absorption spectrometer. The electrothermal $\mathrm{Ge}$ atomisation and signal acquisition $(265 \mathrm{~nm})$ ensued immediately at $2300^{\circ} \mathrm{C}$ for 6 seconds.

The whole system was controlled by a dedicated computer software programme allowing fully automated analytical runs of samples and internal standards. During the development phase, urine samples of laboratory staff personnel were used to characterise the analytical performance of the method. The detection limit of this assay was $0.25 \mu \mathrm{g} \mathrm{Ge} / 1$ urine and its precision (day to day) was $<10 \%$. The results ( $\mu \mathrm{g} \mathrm{Ge} / \mathrm{l}$ ) were normalised to creatinine concentration to account for urine dilution

MEASUREMENT OF Ge IN AIR

Ambient monitoring of Ge concentration was performed in all exposed workers and a representative fraction $(10 \%)$ of controls. Air sampling was carried out with a CIP-10 personal dust sampler (MSA, Saint-Ouenl'Aumone, France). Air was drawn at a flow rate of $10 \mathrm{l} / \mathrm{min}$ through high speed rotary polyurethane foam filters on which the respirable and inhalable dust particles were collected separately. ${ }^{11}$ The Ge content of the dust collected on each filter was measured by AAS with a flame $\left(\mathrm{N}_{2} \mathrm{O} ; \mathrm{C}_{2} \mathrm{H}_{2}\right)$ Varian Spectra AA- 10 or by the FIAS- 400 method already described for urine. Each filter (polyurethane foam) was dissolved with $65 \% \mathrm{HNO}_{3}$ and heated at $120^{\circ} \mathrm{C}$ to obtain a dry residue which was then suspended in $20 \mathrm{ml} 0.1 \mathrm{M} \mathrm{NaOH}$ (solution 1). The concentration of $\mathrm{Ge}$ in this solution was first measured by flame AAS and samples with concentrations $<1.5 \mathrm{mg} / 1$ were reanalysed after 100-fold dilution with $0.2 \mathrm{M}$ $\mathrm{KH}_{2} \mathrm{PO}_{4}$ buffer, $\mathrm{pH}$ 6.0, by the FIAS method which allowed a much lower detection limit. 
Blank measurements of unused foam filters showed that their background Ge content was $<10 \mathrm{ng} \mathrm{Ge} / \mathrm{g}$, representing a Ge concentration $<0.1 \mu \mathrm{g} \mathrm{Ge} / 1$ solution 1. Foam filters spiked with Ge showed recoveries between $95 \%$ and $100 \%$ with both flame and FIAS methods. The measurement precision was characterised by a coefficient of variation $<3 \%$. Three filters spiked with $\mathrm{Ge}$ were measured by the flame and FIAS (after 200-fold to 500-fold dilution) methods and showed similar results. This procedure allowed a reliable measurement of airborne concentrations down to $10 \mathrm{ng} \mathrm{Ge} / \mathrm{m}$.

CLINICAL EXAMINATION, LUNG FUNCTION TESTS, AND RADIOGRAPHS

Each participant was submitted to a routine clinical examination with special attention to lung auscultation and asked to complete an adapted European Coal and Steel Community (ECSC) questionnaire on chronic bronchitis complemented with specific items on renal and liver diseases as well as lifestyle and use of medications.

Vital capacity (VC), forced vital capacity (FVC), forced expiratory volume in 1 second $\left(\mathrm{FEV}_{1}\right)$, peak expiratory flow $(\mathrm{PEF})$, and maximal expiratory flow rate at $75 \%\left(\mathrm{MEF}_{75}\right)$ and $50 \%\left(\mathrm{MEF}_{50}\right)$ of VC were measured with a rolling seal spirometer (Volugraph, Mijnhardt, The Netherlands) with the subject seated. Total lung capacity (TLC) and residual volume (RV) were assessed by the helium dilution method. Measurement of carbon monoxide diffusing capacity $\left(\mathrm{TL}_{\mathrm{CO}}\right)$ was performed by the single breath technique with a Mijnhardt Diffusimat 2000 and the subject seated. A blind interpretation of a full size chest radiograph of each participant was done by two independent physicians certified in respiratory medicine and radiology, respectively.

CLINICAL CHEMISTRY

Potential exposure to other toxic metals was ascertained by the measurement of cadmium and mercury in urine and lead in blood at the end of the working week. Erythrocyte sedimentation rate, haemoglobin content, packed cell volume, blood count (red blood cells, mean corpuscular volume, mean corpuscular haemoglobin, platelets, white blood cell count, and differentials), creatinine, $\gamma$-glutamine transpeptidase $(\gamma \mathrm{GT})$, alkaline phosphatase (AP), aspartate transaminase (AST), and alanine transaminase (ALT) in serum were analysed in Monday morning blood samples. Urinary con- centrations of albumin, transferrin, $\beta 2-$ microglobulin, retinol binding protein, and $\alpha 1$-microglobulin, as well as the activity of $\mathrm{N}$-acetyl- $\beta$-glucosaminidase (total and B-fractions) and kallikrein were assessed in urine samples on Friday after the shift and the results were normalised for creatinine concentration to account for urine dilution..$^{12}$ For kallikrein measurements, only samples with a sodium content $>35 \mathrm{mmol} / \mathrm{g}$ creatinine were considered because severely low intake of sodium may be associated with a pronounced increase of urinary kallikrein activity. ${ }^{13}$ To allow the detection of a possible effect of $\mathrm{Ge}$ exposure over the working week, these variables were measured in urine collected at the end of the working week (Friday after the shift). For practical reasons, urine samples could only be collected on Monday morning in controls. Measurements of urinary biomarkers carried out in controls and a subgroup of exposed subjects did not indicate significant differences between samples collected on Monday morning and at the end of a working week (not shown). Smoking habits were confirmed by the measurement of urinary cotinine concentration. ${ }^{14}$

\section{STATISTICS}

Statistical analyses were by NCSS procedures (NCSS 6.0 Statistical System for Windows, Washington, DC, USA) When variables were not normally distributed, analysis was performed on log transformed data and nonparametric tests were used when log transformation did not normalise the distributions. For stratification analyses, ex-smokers were combined with current smokers. Means were compared by Student's $t$ test or by analysis of variance (ANOVA) complemented by Dunnett's multiple comparison test. Proportions were compared with a $\chi^{2}$ test. A $\mathrm{p}$ value $<0.05$ (two sided) was considered as the criterion of significance.

\section{Results}

POPULATION CHARACTERISTICS

Both populations were well matched for age, height, weight, and smoking habits (table 1). All workers had normal blood lead values and controls had a slightly higher (non-significant) mean blood lead concentration than workers exposed to Ge. No significant difference in urinary concentrations of cadmium and mercury was found between both groups.

Table 1 Characterisitics of the population

\begin{tabular}{lll}
\hline & Control group $(n=79)$ & Exposed group $(n=75)$ \\
\hline Age $(\mathrm{y}) \dagger$ & $38.8(27.5-54.6,6.0)$ & $38.8(27.1-55.0,6.5)$ \\
Height $(\mathrm{cm}) \dagger$ & $175.4(158.0-195.0,7.5)$ & $175.4(153.0-194.0,7.6)$ \\
Weight $(\mathrm{kg}) \dagger$ & $77.9(58.0-105.0,11.0)$ & $79.1(56.0-128.0,10.6)$ \\
Lead in blood $(\mu \mathrm{g} / \mathrm{l}) \ddagger$ & $50.7(17.0-139.0,1.5)^{\star}$ & $39.5(7.0-123.0,1.7)$ \\
Cadmium in urine $(\mu \mathrm{g} / \mathrm{g}$ creatinine $) \ddagger$ & $0.35(0.09-2.29,2.0)$ & $0.25(0.03-1.09,2.1)$ \\
Mercury in urine $(\mu \mathrm{g} / \mathrm{g}$ creatinine $) \ddagger$ & $1.46(0.28-7.30,2.0)$ & $1.61(0.41-7.94,2.0)$ \\
Duration of exposure $(\mathrm{y}) \dagger$ & - & $13.5(1.4-35.0,6.8)$ \\
Smokers/ex-smokers $(\mathrm{n} / \mathrm{n})$ & $27 / 26$ & $6.2(0.1-27.0,3.4)$ \\
Pack-years $($ smokers and ex-smokers) $\ddagger$ & $7.7(0.2-36.0,2.9)$ & $1.65(0.05-3.28,0.80)$ \\
Cotininuria in current smokers $(\mathrm{mg} / \mathrm{g}$ creatinine $) \oint$ & $1.64(0.17-23.23,4.3)$ & \\
\hline
\end{tabular}

${ }^{\star} \mathrm{p}<0.05 v$ exposed group by $t$ test.

†Arithmetic mean (range, SD); łgeometric mean (range, SD); \median (range, SD). 
Ge air - respirable

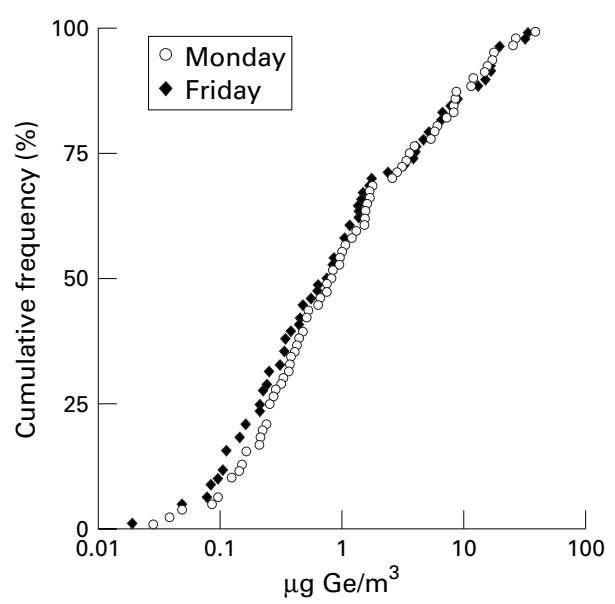

Ge urine - before shift

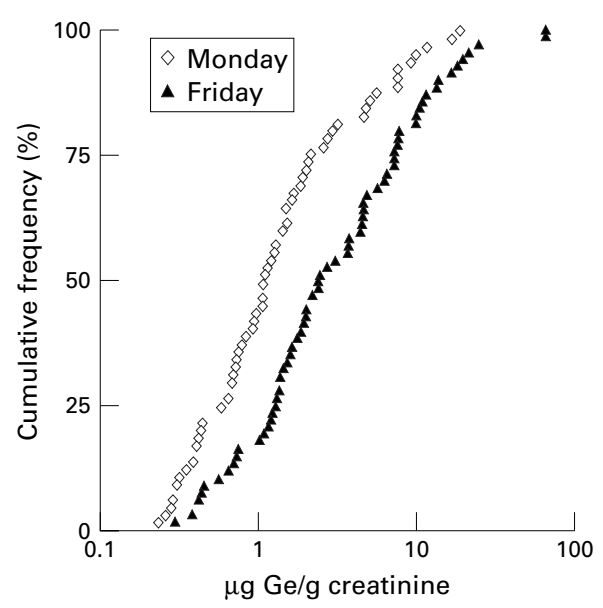

Ge air - inhalable

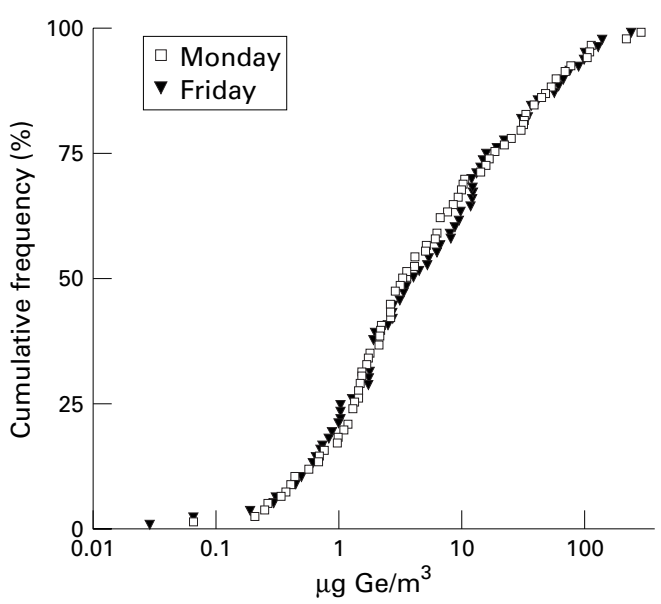

Ge urine - after shift

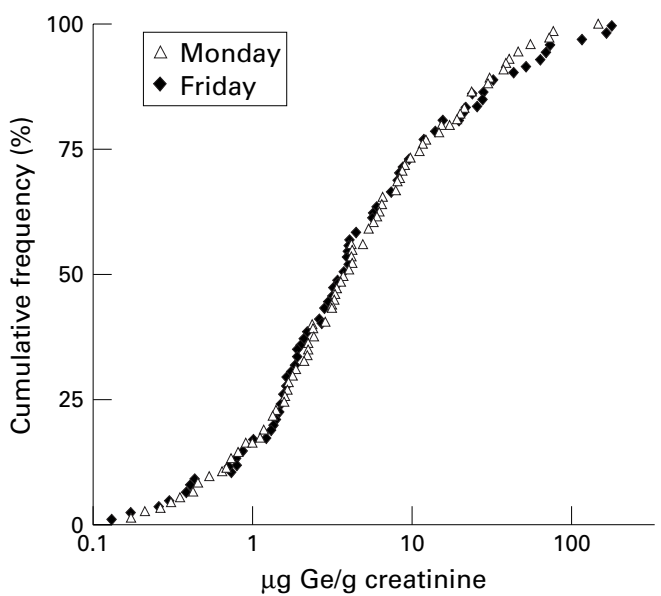

Figure 1 Cumulative frequency distribution of Ge concentrations in air (upper panels) and urine (lower panels).

EXPOSURE ASSESSMENT

The cumulative frequency distribution of $\mathrm{Ge}$ in air is presented in figure 1 (upper panels). For both respirable and inhalable fractions, exposure was remarkably similar on Monday and Friday with geometrical means (GSD) of 1.07 (3.21) versus $0.92(3.98)$ and 5.11 (7.63) versus $5.11(9.19) \mu \mathrm{g} / \mathrm{m}^{3}$, respectively. All results of ambient measurements performed in controls were below the detection limit. Concentrations of $\mathrm{Ge}$ in urine of control workers was always $<0.25 \mu \mathrm{g} / \mathrm{g}$ creatinine. The distribution of $\mathrm{Ge}$ in urine of exposed workers is presented on figure 1 (lower panels). Although urinary Ge before the shift was on the average lower on Monday than on Friday, no difference in

Table 2 Characterisation of exposure

\begin{tabular}{|c|c|c|c|c|}
\hline & \multicolumn{4}{|c|}{ Ge in urine of exposed workers ( $\mu g / g$ creatinine) } \\
\hline & \multicolumn{2}{|l|}{ Before shift $t$} & \multicolumn{2}{|l|}{ After shift } \\
\hline & Monday & Friday & Monday & Friday \\
\hline $\mathrm{n}$ & 65 & 69 & 75 & 75 \\
\hline Geometric mean (GSD) & $1.36(2.50)$ & $3.16(3.61)$ & $4.22(4.96)^{\star}$ & $4.34(5.86)^{\star}$ \\
\hline Median & 1.14 & 2.56 & 3.67 & 3.90 \\
\hline Range & $0.23-20.21$ & $0.30-70.83$ & $0.16-160.00$ & $0.12-194.58$ \\
\hline
\end{tabular}

${ }^{\star} \mathrm{p}<0.01 v$ Monday, before shift (Dunnett's test).

†10 And six samples had Ge concentrations below detection limit, on Monday and Friday, respectively. urinary Ge concentrations after the shift was found between the beginning and the end of the working week (table 2). Ge concentrations measured on Friday in air and urine according to the four different work sites are given in table 3 . On the average, exposure was much more important at the workplace involving Ge metal plus oxides and $\mathrm{Ge}$ oxide plus tetrachloride. This difference in exposure level was also reflected by the urinary concentration of the element measured at the end of the working week. The relation presented on figure 2 shows that the concentration of Ge measured in urine collected at the end of the working week (after the shift) was reasonably well correlated with the intensity of external exposure assessed by the ambient concentration of inhalable Ge particles. A relation was also found between urinary Ge after the shift and the airborne concentration of respirable Ge particles $(r=0.55$, $\mathrm{p}<0.0001)$. Similar relations were found with data collected on Monday (Ge in air $v$ urine after the shift, not shown).

QUESTIONNAIRE AND CLINICAL EXAMINATION

The questionnaire on renal, liver, and respiratory history was analysed separately for smokers and non-smokers and both groups combined. No influence of Ge exposure on the 
Table 3 Characterisation of exposure according to the type of Ge compound involved

\begin{tabular}{|c|c|c|}
\hline & $\begin{array}{l}\text { Ge in air Friday } \\
\text { (inhalable in } \mu g / m^{3} \text { ) }\end{array}$ & $\begin{array}{l}\text { Ge in urine } \\
\text { Friday after shift } \\
\text { ( } \mu / g \text { creatinine) }\end{array}$ \\
\hline Ge metal only & $3.41(1.28)^{\star}$ & $3.37(1.23)$ \\
\hline Ge metal+oxide & $21.71(2.06)$ & $11.75(1.81)$ \\
\hline Ge oxide+tetrachloride & $52.48(2.04)$ & $46.56(1.81)$ \\
\hline Variable & $4.23(1.63)$ & $2.42(1.50)$ \\
\hline
\end{tabular}

${ }^{\star}$ Geometric mean (GSD).

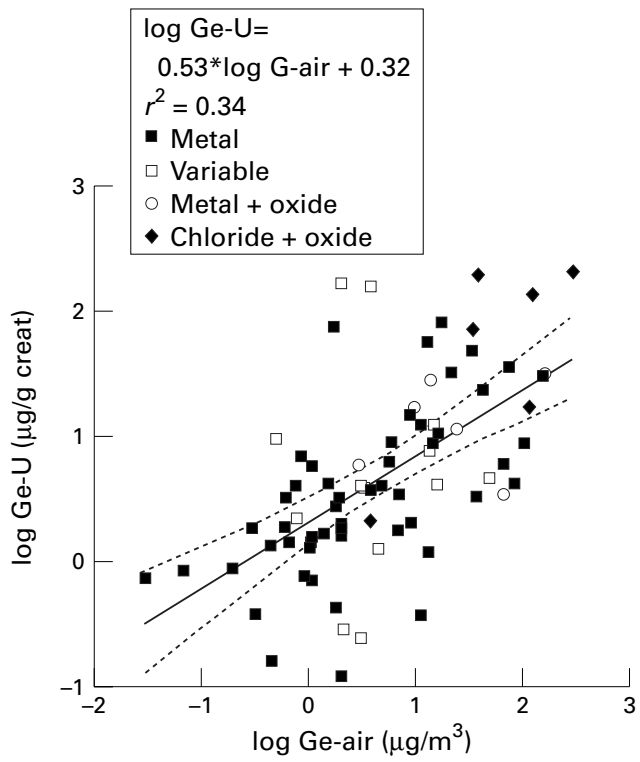

Figure 2 Relation between Ge concentration in air (inhalable fraction) and in urine after the shift samples, both collected at the end of the working week.

prevalence of respiratory symptoms was found (not shown). However, the reporting of wheezing was significantly different in smokers and non-smokers from the exposed group (21\% and $0 \%$, respectively, $\mathrm{p}<0.05)$.

CLINICAL EXAMINATION AND LUNG FUNCTION Clinical examination did not show any difference between controls and workers exposed to Ge. Two way ANOVA (exposure and smoking) did not detect any influence of exposure on lung volumes, ventilatory performances, or single breath lung diffusing capacity (table 4). Likewise the prevalences of lung function variables below the 5th or above the 95th percentile in the control group were not significantly higher in the group exposed to $\mathrm{Ge}$ (not shown). An effect of smoking on several lung function variables (RV, $\mathrm{MEF}_{75}, \mathrm{TLco}$, TLCO/VA, RV/TLC) was, however, clearly identified but no interaction with exposure was found. No radiological lung abnormalities were detected in either the controls or in the exposed subjects.

\section{CLINICAL CHEMISTRY}

All haematological values were within the normal clinical range, except one control subject with an increased mean corpuscular volume $(103 \mathrm{fl})$ associated with a $\gamma \mathrm{GT}$ value of $98 \mathrm{IU} / 1$. No significant difference in the haematological variables was found between exposed workers and controls (not shown). Results of liver markers (table 5) did not show any difference between control and exposed groups. The prevalence of values $>95$ th percentile in the controls was not significantly greater than in the exposed group (not shown).

Urinary variables showed a significant increase of the mean concentration of albumin $(p=0.036)$ and transferrin $(p=0.005)$ in exposed workers compared with controls (table 6). No significant difference was found between both groups for low molecular weight proteins ( $\beta 2-$ and $\alpha 1$-microglobulin, retinol binding protein), N-acetyl- $\beta$-glucosaminidase, or kallikrein. The prevalence of increased values (albumin $>17.6 \mathrm{mg} / \mathrm{g}$ creatinine, transferrin $>832 \mu \mathrm{g} / \mathrm{g}$ creatinine) was also significantly greater in exposed workers than controls $(12.0 v 1.3 \% ; \mathrm{p}=0.006$ and $20 v 8.9 \%$; $\mathrm{p}=0.040$, respectively). A similar analysis performed on $\alpha 1$-microglobulin, $\beta 2$-microglobulin, retinol binding protein, and total $\mathrm{N}$-acetyl- $\beta$-glucosaminidase (cut off values 20 $\mathrm{mg} / \mathrm{g}$ creatinine, $300,300 \mu \mathrm{g} / \mathrm{g}$ creatinine and $4.64 \mathrm{U} / \mathrm{g}$ creatinine) did not show any difference between the groups. Also, urinary variables did not significantly differ according to the type of exposure (metal, metal plus oxide, tetrachloride plus oxide or variable).

No dose-effect relation was found between urinary albumin and exposure as assessed by $\mathrm{Ge}$ in air, $\mathrm{Ge}$ in urine, or duration of exposure.

The urinary concentration of albumin and transferrin was higher in retired Ge workers (geometric mean (SD) 5.89 (20.5) $\mathrm{mg} / \mathrm{g}$ creatinine and 891 (4195) $\mu \mathrm{g} / \mathrm{g}$ creatinine,) than in matched controls (3.86 (0.68) and 334 (354), respectively). This difference was significant for transferrin only $(p=0.04)$. Serum creatinine concentrations were, however, lower in

Table 4 Lung function tests (mean (range, SD))

\begin{tabular}{|c|c|c|c|c|c|c|}
\hline \multirow[b]{2}{*}{ Variable } & \multicolumn{3}{|l|}{ Control group } & \multicolumn{3}{|l|}{ Exposed group } \\
\hline & Non-smokers $(n=26)$ & Smokers $(n=53)$ & Total $(n=79)$ & Non-smokers $(n=24)$ & Smokers $(n=51)$ & Total $(n=75)$ \\
\hline FVC (1) & $5.0(3.5-0.4,0.8)$ & $4.9(3.1-6.2,0.7)$ & $4.9(3.1-6.4,0.7)$ & $5.0(3.1-6.7,0.9)$ & $5.0(3.2-6.5,0.8)$ & $5.0(3.1-6.7,0.8)$ \\
\hline RV (1) & $1.7(0.7-2.5,0.4)$ & $1.9(0.5-3.7,0.6)$ & $1.9(0.5-3.7,0.6)$ & $1.7(0.6-2.9,0.5)$ & $1.9(1.0-3.4,0.5)$ & $1.8(0.6-3.4,0.5)$ \\
\hline TLC (1) & $6.8(5.1-8.6,1.0)$ & $7.0(5.0-8.9,0.9)$ & $6.9(5.0-8.9,0.9)$ & $6.8(5.1-9.5,1.2)$ & $7.0(4.9-9.7,1.0)$ & $6.9(4.9-9.7,1.1)$ \\
\hline RV/TLC (\%) & $25.3(14.0-36.0,4.7)$ & $28.1(7.8-42.3,6.5)$ & $27.2(7.8-42.3,6.1)$ & $24.9(10.5-35.3,5.4)$ & $26.8(15.3-39.8,5.4)$ & $26.2(10.5-39.8,5.4)$ \\
\hline $\mathrm{FEV}_{1}(\mathrm{l})$ & $4.1(2.3-5.5,0.7)$ & $4.0(2.1-4.8,0.5)$ & $4.0(2.1-5.5,0.6)$ & $4.1(2.3-5.5,0.7)$ & $4.0(2.8-5.2,0.7)$ & $4.0(2.3-5.5,0.7)$ \\
\hline $\mathrm{FEV}_{1} / \mathrm{VC}(\%)$ & $82.0(64.3-92.6,6.2)$ & $80.8(68.4-90.3,5.5)$ & $81.2(64.3-92.6,5.7)$ & $82.4(70.1-88.2,5.2)$ & $80.7(59.3-92.9,6.6)$ & $81.2(59.3-92.9,6.2)$ \\
\hline $\operatorname{PEF}(1 / s)$ & $9.8(5.3-12.7,1.7)$ & $9.3(4.8-12.7,1.6)$ & $9.5(4.8-12.7,1.7)$ & $10.2(5.9-14.0,2.0)$ & $9.6(4.3-12.7,1.7)$ & $9.8(4.3-14.0,1.9)$ \\
\hline $\operatorname{MEF}_{75}(1 / \mathrm{s})$ & $2.2(0.5-4.6,1.0)$ & $1.8(0.7-3.0,0.5)$ & $1.9(0.5-4.6,0.7)$ & $2.1(0.5-3.3,0.7)$ & $2.0(0.7-4.1,0.7)$ & $1.9(0.5-4.1,0.7)$ \\
\hline $\operatorname{MEF}_{50}(1 / \mathrm{s})$ & $5.3(1.7-9.0,1.7)$ & $5.0(1.7-8.7,1.4)$ & $5.1(1.7-9.0,1.5)$ & $5.3(2.0-7.6,1.3)$ & $5.0(1.8-10.0,1.6)$ & $5.1(1.8-10.0,1.5)$ \\
\hline \multicolumn{7}{|l|}{ TLCO } \\
\hline$(\mathrm{ml} / \mathrm{min} / \mathrm{mm} \mathrm{Hg})$ & $33.0(22.5-40.7,4.0)$ & $31.5(19.4-54.0,5.8)$ & $32.0(19.4-54.0,5.3)$ & $34.0(23.4-50.6,6.8)$ & $31.4(19.1-43.1,5.3)$ & $32.2(19.1-50.6,5.9)$ \\
\hline $\begin{array}{l}\text { TLCo/VA } \\
(\mathrm{ml} / \mathrm{min} / \mathrm{mm} \mathrm{Hg} / \mathrm{l})\end{array}$ & $5.0(4.2-6.3,0.6)$ & $4.7(3.2-6.2,0.7)$ & $4.8(3.2-6.3,0.7)$ & $5.2(4.0-6.5,0.7)$ & $4.7(3.0-5.9,0.7)$ & $4.8(3.0-6.5,0.7)$ \\
\hline
\end{tabular}


Table 5 Clinical chemistry (serum)

\begin{tabular}{|c|c|c|}
\hline Variable & Control group $(n=79)$ & Exposed group $(n=75)$ \\
\hline Creatinine $(\mathrm{mg} / \mathrm{l})^{\star}$ & $10.3(7.6-13.1,1.1)$ & $10.5(8.1-13.8,1.1)$ \\
\hline$\gamma \mathrm{GT}(\mathrm{IU} / \mathrm{l}) \dagger$ & $22.8(8.0-98.0,1.8)$ & $21.7(9.0-91.0,1.6)$ \\
\hline AST $(I U / 1)^{\star}$ & $20.5(13.0-66.0,6.9)$ & $21.6(12.0-42.0,5.7)$ \\
\hline $\operatorname{ALT}(\mathrm{IU} / \mathrm{l}) \dagger$ & $21.4(10.0-60.0,1.5)$ & $21.4(8.0-57.0,1.5)$ \\
\hline Alkaline phosphatase $(\mathrm{IU} / 1)^{\star}$ & $47.7(18.0-81.0,11.9)$ & $45.8(21.0-81.0,12.4)$ \\
\hline
\end{tabular}

^Arithmetic mean (range, SD); †geometric mean (range, SD).

retired Ge workers than in retired controls (9.9 (0.7) $v 11.2(1.4) \mathrm{mg} / \mathrm{l}$, respectively, $\mathrm{p}<0.01)$.

\section{Discussion}

The present cross sectional study compared male workers exposed to inorganic Ge compounds with a well matched control group. The Ge workers were exposed for $>10$ years to a geometric mean airborne concentration of about $5 \mu \mathrm{g} \mathrm{Ge} / \mathrm{m}^{3}$ (inhalable). High concentrations up to $300 \mu \mathrm{g} \mathrm{Ge} / \mathrm{m}^{3}$ were found in the dry part of the production process. Although selection bias (healthy worker effect) cannot be formally excluded in the framework of a cross sectional study, it is unlikely that it may significantly have affected our results because of the remarkable stability of the workforce in this plant.

The high airborne concentrations were reflected by increased concentrations of $\mathrm{Ge}$ in urine up to $200 \mu \mathrm{g} / \mathrm{g}$ creatinine among workers occupied at these workplaces. Measurement of trace amounts of $\mathrm{Ge}$ in biomaterials requires a highly sensitive and accurate method. Atomic absorbtion spectroscopy involving $\mathrm{GeH}_{4}$ formation showed surprisingly poor sensitivity (detection limits 10-500 $\mu \mathrm{g}$ Ge/l) compared with other elements that form hydrides (arsenic, mercury, selenium, etc), despite different attempts to improve atomisation conditions of the heated quartz cell or graphite tube. ${ }^{15} 16$ Recently it has been shown that the detection limit of elements that form hydrides can be considerably improved by use of a graphite electrothermal atomiser for both hydride trapping and cell atomisation, and by coating the graphite tube with a specific trapping reagent. ${ }^{17}$ The method developed for this study was sufficiently sensitivity for biomonitoring, and proved to be reliable and accurate.

The results collected during this survey indicate that the measurement of urinary Ge reflects recent exposure to this metal and that it can be proposed for biomonitoring in occupational medicine. In this particular industrial setting with a stable exposure as illustrated by the air concentrations on Monday and Friday, the measurement performed on a urine sample collected at the end of the shift reflected with a reasonable confidence the intensity of exposure. The slightly lower urinary $\mathrm{Ge}$ values measured in Monday morning samples compared with Friday morning are likely to indicate the longer elimination over a weekend without exposure. The present results do not show a distinct behaviour of Ge according to the species involved (metal, oxide, or chloride), but it should be recognised that the number of observations in each subset was relatively limited and did not allow detection of small differences.

Experimental studies have indicated lung toxicity of $\mathrm{Ge}$ metal and to a lesser extent $\mathrm{GeO}_{2}$ in rats exposed by inhalation for up to 4 weeks. The effects consisted of a relation between concentration of $\mathrm{Ge}$ and accumulation of particulate material in the lungs of all exposed rats, and increased lung weights and number of macrophages. Alveolitis was found in rats exposed to $250 \mu \mathrm{g} \mathrm{GeO}_{2} / \mathrm{m}^{3}$. $^{89}$ Thickening of the alveolar membrane was found 7 months after a single intratracheal administration of 30-70 $\mu \mathrm{g} \mathrm{GeO}_{2}$ in rats. ${ }^{1}$ The present study did not show any impairment of lung function in Ge workers, indicating that at this concentration of chronic exposure $\mathrm{Ge}$ has no deleterious effect on the lung.

No increase in liver markers could be found, which is consistent with other data from case reports, ${ }^{18}{ }^{19}$ although other authors have reported liver dysfunction after oral treatment of rats with high doses of $\mathrm{GeO}_{2}{ }^{20}$

A slight effect of exposure to $\mathrm{Ge}$ on the glomerulus was suggested by a slight but significant increase of urinary albumin concentrations in exposed workers, although no evidence of renal dysfunction was found by the measurement of serum creatinine concentrations. The limited observations in retired workers (possibly exposed to higher Ge concentrations in the past) suggest that this effect may persist after the end of exposure without evidence of a progression to reduced glomerular filtration rate. A similar effect has been found in rats and humans exposed to cadmium, and in that case it has been hypothesised that the increased urinary excretion of anionic high molecular weight proteins - such as albumin - might be the result of a significant decrease of glomerular basement membrane negative charges. Similar glomerular lesions are also encountered in early diabetic glomerulopathy. ${ }^{21}$ The present finding could be consistent with earlier studies that reported glomerular damage after chronic intake of compounds

Table 6 Clinical chemistry (urine) (geometric mean (range, SD))

\begin{tabular}{lcc}
\hline Variable & Control group $(n=79)$ & Exposed group $(n=75)$ \\
\hline Albumin $(\mathrm{mg} / \mathrm{g}$ creatinine) & $4.1 \quad(0.4-45.7,1.9)$ & $5.5^{\star}(0.6-128.5,2.7)$ \\
Transferrin $(\mu \mathrm{g} / \mathrm{g}$ creatinine) & $226.9(31.1-1943.8,2.5)$ & $356.4^{\star}(40.0-4517.5,2.9)$ \\
$\beta 2$-microglobulin $(\mu \mathrm{g} / \mathrm{g}$ creatinine) & $58.9(2.7-237.5,2.2)$ & $62.3(3.2-323.2,2.3)$ \\
Retinol binding protein $(\mu \mathrm{g} / \mathrm{g}$ creatinine) & $50.4(8.8-194.0,2.1)$ & $50.9(10.8-1445.6,2.2)$ \\
$\alpha 1$-microglobulin $(\mathrm{mg} / \mathrm{g}$ creatinine) & $2.95(0.46-68.00,2.2)$ & $3.02(0.46-15.76,2.4)$ \\
N-acetyl- $\beta$-glucosaminidase-B $(\mathrm{U} / \mathrm{g}$ creatinine) & $0.10(0.02-0.99,2.0)$ & $0.11(0.02-0.58,2.1)$ \\
N-acetyl- $\beta$-glucosaminidase-total (U/g creatinine) & $0.88(0.43-3.98,1.6)$ & $0.91(0.21-4.97,1.7)$ \\
Kallikrein (U/g creatinine) $\dagger$ & $0.34(0.01-3.09,2.7)$ & $0.34(0.03-2.58,2.4)$ \\
\hline
\end{tabular}

${ }^{\star} \mathrm{p}<0.05 v$ the control group by $t$ test.

†All values of kallikrein from samples with sodium content $<35 \mathrm{mmol} / \mathrm{g}$ creatinine were omitted. Remaining numbers in control and exposed groups were 66 and 67 , respectively. 
containing Ge. ${ }^{18}{ }^{19}$ However, the fact that we did not find a relation between these changes and the intensity of exposure suggests prudence in the interpretation of the causality of this association.

No significant difference between controls and the exposed group was found for kidney tubular markers. This contrasts with earlier case reports ${ }^{18}{ }^{19}$ that reported increased tubular markers after oral ingestion of elixirs containing Ge. This difference may be explained because those elixirs had much higher doses and mainly contained other Ge compounds.

In conclusion, this study showed the possibility of detecting occupational exposure to inorganic $\mathrm{Ge}$ and compounds by the measurement of the urinary concentration of the element. We did not detect liver or respiratory effects in workers chronically exposed to concentrations of airborne $\mathrm{Ge}$ as high as 300 $\mu \mathrm{g} / \mathrm{m}$. Minor glomerular changes without apparent renal dysfunction were found in exposed workers. Based on these findings, it is prudent to recommend the monitoring of renal markers in workers exposed to Ge.

This study was performed with the financial support of Union Minière SA, Belgium. We are deeply indebted to Drs I Goncette and $\mathrm{O}$ Vandenplas for interpreting chest radiographs.

1 Vouk V. Germanium. In: Friberg L, Nordberg GF, Vouk V, eds. Handbook on the toxicology of metals. Amsterdam: Elsevier; 1986;11:255-66.

2 Schauss AG. Nephrotoxicity and neurotoxicity in humans from organogermanium compounds and germanium dioxide. Biol Trace Elem Res 1991;29:267-80.

3 Tao SH, Bolger PM. Hazard assessment of germanium supplements. Regul Toxicol Pharmacol 1997;25:211-19.

4 van der Spoel JI, Stricker BH, Esseveld MR, et al. Dangers of dietary germanium supplements. Lancet 1990;336:117.

5 Sanai T, Okuda S, Onoyama K, et al. Chronic tubulointerstitial changes induced by germanium dioxide in compari- son with carboxyethylgermanium sesquioxide. Kidney Int 1991;40:882-90.

6 Higuchi I, Izumo S, Kuriyama $M$, et al. Germanium myopathy: clinical and experimental pathological studies. Acta Neuropathol Berl 1989;79:300-4.

7 Seaborn CD, Nielsen FH. Effects of germanium and silicon on bone mineralization. Biol Trace Elem Res 1994;42:15164 .

8 Arts JH, Til HP, Kuper CF, et al. Acute and subacute inhalation toxicity of germanium dioxide in rats. Food Chem Toxicol 1994;32:1037-46.

9 Arts JH, Reuzel PG, Falke HE, et al. Acute and sub-acute inhalation toxicity of germanium metal powder in rats. Food inhalation toxicity of germani.
Chem Toxicol $1990 ; 28: 571-9$.

10 Furst A. Biological testing of germanium. Toxicol Ind Health 1987;3:167-204.

11 Kenny LC, Aitken R, Chalmers C, et al. A collaborative European study of personal inhalable aerosol sampler performance. Ann Occup Hyg 1997;41:135-53.

12 Lauwerys RR, Bernard AM, Roels HA, et al. Cadmium: exposure markers as predictors of nephrotoxic effects. Clin Chem 1994;40:1391-4.

13 Margolius HS, Horwitz D, Geller RG, et al. Urinary kallikrein excretion in normal man. Relationships to sodium intake and sodium-retaining steroids. Circ Res 1974;35:812-19.

14 Haufroid V, Hotz P, Carbonnelle P, et al. Relationships between smoking habits, smoking-associated hematological changes, and urinary benzene metabolites. $\mathcal{F}$ Toxicol Environ Health 1997;52:1-17.

15 Andreae O, Froelich N. Determination of germanium in natural waters by graphite furnace atomic absorption spectrometry with hydride generation. Anal Chem 1981;53: 287-91.

16 Inui $\mathrm{T}$, Terada $\mathrm{S}$, Tamura $\mathrm{H}$, et al. Determination of germanium by hydride generation with reducing tube followed by graphite furnace atomic absorption spectrometry using $\mathrm{CH} 4 / \mathrm{Ar}$ as sweeper gas. Fresenius Z Anal Chem 1983;315: 598-601.

17 Shuttler L, Feuerstein M, Schlemmer G. Long-term stability of a mixed palladium-iridium trapping reagent for in situ hydride trapping with in a graphite electrothermal atomiser. $\mathcal{F}$ Anal Atomic Spectrometry 1992;7:1299-301.

18 Matsusaka T, Fujii M, Nakano T, et al. Germanium-induced Matsusaka T, Fujii M, Nakano T, et al. Germanium-induced
nephropathy: report of two cases and review of the nephropathy: report of two cases and
literature. Clin Nephrol 1988;30:341-5.

19 Okada K, Okagawa K, Kawakami K, et al. Renal failure caused by long-term use of a germanium preparation as an elixir. Clin Nephrol 1989;31:219-24.

20 Sanai T, Oochi N, Okuda S, et al. Subacute nephrotoxicity of germanium dioxide in the experimental animal. Toxicol Appl Pharmacol 1990;103:345-53.

21 Bernard A, Amor AO, Goemare Vanneste J, et al. Urinary proteins and red blood cell membrane negative charges in diabetes mellitus. Clin Chim Acta 1990;190:249-62. 